\title{
Nutritional, Phytochemical, Phenolic Compound Analysis of Piper Cubeba Extract as a Food Fortified
}

\author{
Ramal Ahmed ${ }^{1}$, Sundus Hameed ${ }^{2}$ \\ University of Garmian, College of Education, Chemistry Department \\ University Of Almustansria, College of Science, Biology Department
}

\begin{abstract}
:
Indian spices that provide flavor, color, and aroma to food also possess many therapeutic properties. So the present study was aimed to extract the phytochemical compounds in Piper cubeba, used as food fortifiers. The extract was investigated for the richness of its bioactive compounds. The aqueous of $P$. cubeba extract was subjected to sensitive gas chromatography - mass spectroscopy GC-MS analysis revealed 10 chemical constituents. Extract exhibits potentially bioactive major constituents like Cyclohexanol, Carbamic acid, pMethoxyamphetamine, Bioxirane and Linalol. Further presented the total carbohydrate, elements, such as $\mathrm{Ca}, \mathrm{Mg}, \mathrm{Se}, \mathrm{K}$ and $\mathrm{Fe}$ were in highest proportion in the aqueous extract of Piper cubeba. The aqueous extract was injected to HPLC to detect the phenolic compounds in the extract like Gallic acid, Caffeic acid,Syringic acid, Ferulicacid,Rutin and Catechin. We have investigated the antimicrobial activity of water extract from $P$. Cubeba against major skin pathogens Staphylococccus aureus, Pseudomonas aeruginosa, Proteus vulgaris and Koucria rosia. . The presence of some phytochemicals (saponins, alkaloids, flavonoids, cardiac glycosides, tannins and terpenoids) and some essential minerals proves that it is really an alternative source of medicine.
\end{abstract}

Keyword: P. Cubeba extract, phytochemical analysis, Antibacterial, Minerals, GC-MS, DPPH and HPLC,

\section{Introduction:}

The fruits of $P$. Cubeba L. (Piperaceae) are unremarkably called as cubeba in Arabic and in English called piper. They are spices and possess various medicinal properties ${ }^{(1)} . P$. cubeba is employed by the standard drugs professional in treating acute jaundice. In associate degree earlier study ethanolic extract of $P$. cubeba has been shown to reinforce the activity of pioglitazone and act synergistically in lowering the glucose level in rats ${ }^{(2)}$. The phytochemical profile of Piper species is characterised by the assembly of typical categories of copmpounds like, carboxylicacid acids, and chromenes, moreover asterpenes, phenylpropanoids, lignans, different phelolics and series of alkaloids ${ }^{(3)}$. These compounds exhibit of physiological properties, like antiinflammatory, antimicrobial and inhibitor effects. Though a 
good quantity of analysis has been performed to work out the bactericide activity of meditative plants, optimum extraction of bioactive compounds has not been well established for many plants. Sadly, the event of microorganism resistance to those antimicrobials quickly diminished this optimism. Therefore, can usage concentrations of Pepper cubeba alkaloids and phenols antimicrobial activity against a number of human humiliates bacterium $\left({ }^{4)}(5)\right.$. The dried cubeb berries contain volatile oil consisting monoterpenes (sabinene 50\%, $\alpha$-thujene, and carene) and sesquiterpenes (caryophyllene, copaene, $\alpha$ - and $\beta$-cubebene, $\delta$ - cadinene, germacrene), the sesquiterpenes 1,4 - and 1,8cineole and also the alcohol cubebol. Concerning $15 \%$ of a volatile oil is obtained by distilling cubebs with water. Cubebene, the fluid portion, has the formula $\mathrm{C}_{15} \mathrm{H}_{24}$. It's a pale inexperienced or blue-yellow viscous liquid with a heat woody, slightly natural resin odor $^{(6)}$. The study was designed to investigate the phycochemicals potential in $P$. Cubeba, phenolic compound by using HPLC and, environment-friendly formulations using GC-MS .

\section{Material and Methods}

2.1 Extraction of the plant: $50 \mathrm{gm}$ of dry powdered fruits of $P$. Cubeba were extracted successively with double distilled water (200ml.) for $24 \mathrm{hrs}$. Then collected solutions were filtered through Whatman No-1 filer paper. The extracts were evaporated to dryness at $40 \mathrm{C}^{0}$ by Rotary vacuum evaporator to obtain the respective extracts and stored in a freeze condition at $-20 \mathrm{C}^{0}$ until used for further analysis

\subsection{GC-MS Analysis}

GC-MS analysis was carried out by using GC-MS. Shimadzu Model QP-2010 Mass spectrometer under the following conditions: HP-5 MS (5\% phenylmethylsiloxane) capillary column $(30 \mathrm{~m} \times 0.25 \mathrm{~mm}$ ID film thickness $0.25 \mu \mathrm{m})$. Inert gas of helium was used as a carrier gas at constant flow rate of $1.61 \mathrm{ml} /$ minute. Injection port temperature and interface temperature were set at 230 and $245^{\circ} \mathrm{C}$ respectively. Ion Source Temperature was $250^{\circ} \mathrm{C}$. Initial column temperature was $60 \mathrm{oC}$, held for 2 minute and increased at $70 \mathrm{oC} / \mathrm{min}$ to $305 \mathrm{oC}$ and held for $5 \mathrm{~min}$. An electron ionization system with ionization energy $70 \mathrm{eV}$ was used for the detection of compounds. $75 \mathrm{mg}$ of Methanol leaf extract samples were taken and made up to $15 \mathrm{ml}$ with methanol, from which $1 \mu 1$ of sample was automatically injected (split mode) in the column and mass spectral scan range was set at 45-500 amu. The split ratio was of 1:15. The mass spectrum of the unknown component was compared with the spectrum of the 
known components stored in the Wiley library. The name, molecular weight, and structure of the components of the test material were finally ascertained.

\subsection{Extraction and isolation of phenolic compounds for HPLC analysis}

One gram of the powder plant sample was mixed with $10 \mathrm{ml}$ of ethanol $70 \%$. The mixture was stirred for 24 hours in the dark, and then it was centrifuged for 5 minutes, at 3000 rpm. The ethanol fraction of the supernatant was removed using a rotatory evaporator. Further, the aqueous extract was subjected to acid hydrolysis $(1 \mathrm{~N} \mathrm{HCl})$ for 2 hours at $80^{\circ} \mathrm{C}$. The aglycones were extracted 3 times with ethyl acetate by continuous stirring and then centrifuged at $5000 \mathrm{rpm}$, for 5 minutes. The solvent wasremoved by using water bath at $35^{\circ} \mathrm{C}$. The residue resulting after evaporation was dissolved in first mobile phase,filteredthrought $0.45 \mu \mathrm{m}$ filters (Millex-LG, Millipore), and subjected to HPLC analysis ${ }^{(34)}$.

2.3.1 HPLC Separation of phenolic compounds: A Shimadzu HPLC system equipped with a LC20AT binary pump, a degaser, a SPD-M20A diode array detector (Shimadzu Corp, Kyoto, Japan) and a SUPELCOSIL TM LC-18 column (Siga-Aldrich Co), 5 $\mu \mathrm{m}, 25 \mathrm{~cm}$ x 4.6 mm was used. Gradient elution was performed with mobile phase A, composed of methanol: acetic acid: double distilled water (10:2:88 v/v/v) and mobile phase B, comprising methanol: acetic acid: double distilled water (90:3:7 v/v/v) at (0-5 min)40\%(6-11 min) 50\%(12-17min) $60 \%(18-25 \mathrm{~min}) 70 \%$, at a flow rate of $1.0 \mathrm{ml} / \mathrm{min}$. All solvents were HPLC grade solvents, filtered through a $0.45-\mu \mathrm{M}$ membrane (Millipore, U.S.A.) and degassed in an ultrasonic bath before use. The chromatograms were monitored at $280 \mathrm{~nm}$. The following pure standards were used to quantify the bioactive compounds in the leaves, stems of host andparasite and fruit of parasite: Gallic acid, Caffeic acid,Syringic acid, Ferulicacid,Rutin and Catechin.

2.4 Total Phenolic Content: Phenolic contents of crude extract were measured using Folin Ciocalteu's. Measured at $720 \mathrm{~nm}$ and total phenolic content was calculated with a ascorbic acid standard and expressed as ascorbic equivalent per $\operatorname{gram}^{(7)}$.

2.5 Determination of Total Soluble Carbohydrate: Total carbohydrates was assay by adding Perchloric Acid HCLO4 (1N) to extract was described by Joslyn(1970).measured at $490 \mathrm{~nm}$ and total carbohydrates was calculated with a glucose powder and expressed equivalent per gram $^{(35)}$.

2.6 Antimicrobial activity: To determination of antibacterial activity, Preparation of the aqueous extract by dissolving $1 \mathrm{~g}$ of dried plant extract powder in $10 \mathrm{ml}$ distilled water and 
sterilizer,. And filtered with paper Whatman No.1 to get clear solution of extract, the water extract was refrigerated at a temperature of 4-5 Celsius to avoid the occurrence of chemical changes with the watermelon taking into account the use of extract in antimicrobial studies the duration of the study should not exceed two to three days maximum ${ }^{(36)}$. Four types of antibacterial were (2 negative gram, Pseudomonas aeruginosa and Escherichia coli) and (2 positive gram, Staphylococcus aureus and Kocuria rosea) .

\subsubsection{Antimicrobial activities:}

Agar well diffusion method was done to screen antimicrobial activities for best media and solvent extraction of antimicrobial metabolites, against tested microbial pathogens. Using sterile swabs, Mueller Hinton agar plates inoculated with microbial pathogens then dug wells of $6 \mathrm{~mm}$ diameter using Pasteur pipette $60 \mathrm{ul}$ of the extracts were loaded into wells and the plates were incubated at $37^{\circ} \mathrm{C}$ for 24 hours. The plates were observed for zone of inhibition (8)

In a total of antibiotics were used for each type of positive to compare the effectiveness of the water extracts of the studied species with the effectiveness of the antibiotic. (VA) Vancomycin against the growth of $S$. aureus bacteria with a concentration of $30 \mathrm{mg}$ and antagonist. (RA) Rifampin against the growth of Kocuria rosea with a concentration of $5 \mathrm{mg}$ and antagonist (AK) Amikacin. Against E. coli growth of $10 \mathrm{mg}$ and IMipenam against the growth of $P$. aeruginosa at a concentration of $10 \mathrm{mg}^{(9)}$.

\subsection{Qualitative screenings of phytochemicals}

The qualitative screenings of powdered crude drugs for their active ingredients were carried out using the following standard procedures ${ }^{(10)(32)(33)}$.

\section{Results and Discussion:}

The present study shown that the aqueous extracts of fruit parts of $P$. Cubeba contained cyclohexanol, Carbamic acid, , 1,4,7-Cycloundecatrien, phenols, , Alpha-Pinene, Phenethylamine, benzene, 1,4-bis, terpenoids, Linalol and Bioxirane (Table 1).

In the formerly study, it has been reported that the identified compounds exert significant biological activity has antioxidant, antibacterial and prophylactic activities ${ }^{(11)}$. Carbamic acid has a pharmacology, displaying antiprotozal, antimicrobial, anti-inflammatory, antitumor and chemoprevention properties ${ }^{(12) .}$ Hexahydro, Copaene has showing antifungal, antioxidant, hypocholesterolemic nematicide, pesticide, anti-androgenic, p-Methoxyamphetamine inhibitor, potent antimicrobial activity, aqueous extract preferred for the extraction of antioxidant compounds mainly because its lowers toxicity, the antioxidant activities of the 
individual compounds may depend on structural factors, such as the number of phenolic hydroxyl or methoxyl groups, flavone hydroxyl, keto groups, free carboxylic groups and other structural features Piper species, commonly used in diet and traditional medicine, were assessed for their antioxidant potential ${ }^{(13)}$.

Table (1): GC-MS analysis of phytochemicals identified of P.Cubeba aqueous extract

\begin{tabular}{|c|c|c|c|}
\hline No. & Retention time & M. formula & Name of the compound \\
\hline 1 & $\mathbf{3 . 7 5 0}$ & $\mathrm{C}_{6} \mathrm{H}_{12} \mathrm{O}$ & Cyclohexanol, Phenol, hexahydro- \\
\hline 2 & $\mathbf{4 . 9 1 0}$ & $\mathrm{C}_{9} \mathrm{H}_{14} \mathrm{C}_{1} \mathrm{NO}_{2}$ & $\begin{array}{c}\text { p-Methoxyamphetamine, Phenethylamine, p-methoxy-.alpha.- } \\
\text { methyl. }\end{array}$ \\
\hline 3 & $\mathbf{6 . 6 1 5}$ & $\mathrm{C}_{17} \mathrm{H}_{23} \mathrm{~N}_{3} \mathrm{O}$ & $\begin{array}{c}\text { Carbamic acid, N-[(N-cyanomethylpropanamide)-2-yl]-, 1- } \\
\text { methyl-1-(3,5-dimethoxyphenyl)ethyl ester }\end{array}$ \\
\hline 4 & $\mathbf{6 . 7 1 0}$ & $\mathrm{C}_{4} \mathrm{H}_{8} \mathrm{O}_{2}$ & $1,2: 3,4-$-Diepoxybutane, Bioxirane \\
\hline 5 & $\mathbf{7 . 3 8 5}$ & $\mathrm{C}_{12} \mathrm{H}_{10} \mathrm{FN}_{5}$ & $243: 1$ H-Purin-6-amine, [(2-fluorophenyl)methyl]- (CAS) \\
\hline 6 & $\mathbf{8 . 7 1 5}$ & $\mathrm{C}_{12} \mathrm{H}_{22} \mathrm{SiO}_{2}$ & BENZENE, 1,4-BIS(TRIMETHYLSILYL \\
\hline 7 & $\mathbf{9 . 4 8}$ & $\mathrm{C}_{10} \mathrm{H}_{16}$ & Alpha-Pinene \\
\hline 8 & $\mathbf{1 2 . 2 1}$ & $\mathrm{C}_{15} \mathrm{H}_{24}$ & Copaene \\
\hline 9 & $\mathbf{1 5 . 7 9}$ & $\mathrm{C}_{15} \mathrm{H}_{24}$ & $1,4,7$-Cycloundecatrien,1,5,9,9-tetramethylZ,Z,Z-100 \\
\hline 10 & $\mathbf{1 0 . 8 2}$ & $\mathrm{C}_{10} 5 \mathrm{H}_{18} \mathrm{O}$ & Linalol \\
\hline
\end{tabular}

In the present study, plant phenolic compounds show (Table 2), the highest phenolic Ferulic acid (11ppm) and lowest was Syringic acid (3ppm). Medicinal plants are an important source of antioxidants natural anti-oxidants increase the anti-oxidant capacity of the plasma and reduce the risk of certain. Polyphenols are the key plant combinations with anti-oxidant activity. Usual phenolics that have anti-oxidant activity are recognized to be mainly phenolic acids and flavonoids ${ }^{(37)}$. The major plant phenolic can be divided into four common groups: phenolic acids (gallic, protochatechuic, caffeic, and rosmarinic acids, phenolic diterpenes (carnosol and carnosic acid), flavonoids (quercetin and catechin), and volatile oils compounds (eugenol, carvacrol, thymol, and menthol.. Phenolic acids generally act as antioxidants by trapping free radicals; flavonoids can scavenge free radicals and chelate metals as well ${ }^{(17)}$. The phenolic compound found an initial increase in antioxidative activity followed by a subsequent decrease for all solution combinations. The effect improver for catechin and epicatechin. These compounds may be acting independently, while other combinations may react with each other ${ }^{(14)}$. Many have strong antiradical activity. Most of the phenolic compounds found in red wines are derived from the condensation of flavan-2-ol into 
oligomers (proanthocyanidins) and polymers (condensed tannins). Resveratrol, quercetin, and rutin are generally found in grape skin extracts, while catechin and epicatechin are found in the seeds. $\left({ }^{15)}\right.$. Some type of phenols can polymerize into polyphenols that can bind minerals. Proanthocyanidins often occur as oligomers or polymers of monomeric flavonoids, polyhydroxy flavan-3-ols such as $[+]$ catechin $\left({ }^{15)}\right.$ The polymeric procyanidins are better antioxidants than the corresponding monomers, catechin, and epicatechin, Catechin and epicatechin can combine to form esters, such as catechin/epicatechin gallate, or bond with sugars and proteins to yield glycosides and polyphenolic proteins. Glycosylation of flavonoids at the $3-\mathrm{OH}$ group usually decreases the antioxidative activity due to the reduction of the number of phenolic groups ${ }^{(16)}$.

Table (2): PHLC analysis for phenolic compounds (ppm) of Pipper cubeba

\begin{tabular}{|c|l|l|l|l|l|l|}
\hline No. & Rutin & Gallic acid & Ferulic acid & Cafic acid & Catechin & Syringic acid \\
\hline Phenolic & & & & & \\
\hline Piper cubeba & $8 \mathrm{ppm}$ & $8 \mathrm{ppm}$ & $11 \mathrm{ppm}$ & $13 \mathrm{ppm}$ & $5 \mathrm{ppm}$ & $3 \mathrm{ppm}$ \\
\hline
\end{tabular}

\section{DPPH free radical scavenging activity}

Table 3 shows the results of the free radical (DPPH) scavenging activity in \% inhibition. The result revealed that the aqueous fraction of $P$. Cubeba exhibited the highest radical scavenging activity with $70.36 \mathrm{mg} / \mathrm{ml}$. The stable radical DPPH has been used widely for the determination of primary anti-oxidant activity. It is accepted that the DPPH free radical scavenging by antioxidants is due to their hydrogen donating ability ${ }^{(19)}$. The collected fruit extracts exhibited remarkable DPPH free radicals scavenging ability at different concentrations. From these, the \% inhibition concentrations and IC50's were calculated. IC $_{50}$ value is definite as the absorption of substrate that causes $50 \%$ damage of the DPPH activity and was considered by linear regression mentioned of plots of the percentage of antiradical activity against the concentration of the tested compounds. Results showed in (Table 3) reports no $\mathrm{IC}_{50}$ value in water extraction of plants. Only aqueous extract of the P. Cubeba plants showed an $\mathrm{IC}_{50}$ value of $70.36 \mathrm{mg} / \mathrm{ml}$. The antioxidant activity of $P$. Cubeba extracts rise with the increase the polyphenol compounds of the herbal extract, A linear relationship between the reciprocal of $\mathrm{IC}_{50}$ value and the total polyphenol content of P. Cubeba was observed in this study, indicating that increasing the polyphenol content strengths the antioxidant activity ${ }^{(18)}$. In the (table 3 ) Shawn that the total carbohydrate of P.Cubeba $15 \%$. The superfluous carbohydrates composed in oil palm seedlings in the present study might be 
channelled for the manufacture of secondary metabolites (total phenolics and flavonoids). Carbohydrates are the basic compounds required to produce phenolics compound through shikimic acid pathway where extra carbohydrates derived from glycolysis and the penthose phosphate pathway are converted into the aromatic amino acid ${ }^{(20)}$ They are used for many cell functions and cellular structures and as storage of energy. Under autotrophic conditions, green microalgae use photosynthesis to produce and accumulate carbohydrates and ATP ${ }^{(21)}$. They exhibition anti-oxidant activity by incapacitating lipid free radicals or avoiding decomposition of hydro peroxides into free radicals P. Cubeba showed the highest Phenolic content the result of total phenol compound reveals in the table 3.

Table (3): DPPH and Total phenol and carbohydrate of Pipper cubeba

\begin{tabular}{|c|c|c|c|}
\hline Plant & Total carbohydrates & Total phenol & IC $_{\mathbf{5 0}}$ \\
\hline Pipper cubeba & $15 \%$ & $2.11 \mathrm{mg} / \mathrm{gm} \mathrm{D.W}$ & $70.3622 \mathrm{mg} / \mathrm{ml}$ \\
\hline
\end{tabular}

\section{Minerals Analysis of $P$. cubeba extract}

Table (4) shows that the mineral composition of , P. cubeba, extract. The extract was content different mineral content,. Zinc was found higher levels in P. cubeba extract was (13.90 $\mathrm{mg} / \mathrm{kg}$ ) compared with the Se. $P$. cubeba extract was content $(42.4 \mathrm{mg} / \mathrm{kg}$ of Fe and $12 \mathrm{mg} / \mathrm{kg}$ of Mn. Minerals are known to play important metabolic and physiologic roles in the living system, Iron, zinc, selenium and manganese strengthen the immune system as antioxidants ${ }^{(25)}$. Magnesium and phosphorus, Iron, zinc, and manganese were present but not in very high concentration are essential minerals for life important in the formation of bones and teeth as a cofactor for enzymes and a component of ATP, DNA, RNA and cell membranes respectively (26). The minerals present in low concentration (iron, zinc, copper and manganese) perform various important functions in humans like the formation of hemoglobin, growth and sexual maturation, facilitating iron intake, as cofactor for enzymes and so many other functions ${ }^{(27)}$.

Table (4): minerals copmpund of Pipper cubeba

\begin{tabular}{|c|c|c|}
\hline NO. & $\begin{array}{c}\text { Minerals } \\
\mathbf{~ m g / k g}\end{array}$ & P. cubeba \\
\hline 1 & $\mathrm{Zn}$ & 13.90 \\
\hline 2 & $\mathrm{Se}$ & 1.05 \\
\hline 3 & $\mathrm{Mg}$ & 1033 \\
\hline 4 & $\mathrm{P}$ & 225.1 \\
\hline 5 & $\mathrm{Fe}$ & 42.4 \\
\hline 6 & $\mathrm{Mn}$ & 12 \\
\hline 7 & $\mathrm{Co}$ & 00 \\
\hline
\end{tabular}




\section{Phytochemical screening of P.Cubeba extract}

In the present study, preliminary phytochemical testing shows (Table 5), the presence of high amount of alkaloids, tannins, phenolics and other all the principal secondary metabolites were detected in aqueous extract of Piper cubeba. The living system is protected from this by enzymes such as superoxide dismutase, glutathione peroxidase and catalase and certain endogenous antioxidant such as $\alpha$-tocopherol, ascorbic acid, $\beta$-carotene and uric acid, since the endogenous antioxidants acting as intracellular defense systems protecting cells from free radicals damage and extensive lyses ${ }^{(28)}$.

Scavenging and diminishing the formation of oxygen-derived species are not $100 \%$ efficient, micro nutrients or antioxidants taken as supplements are particularly important in diminishing the cumulative oxidative damages ${ }^{(29)}$. The biochemical basis enhanced drug availability by piperine. The phytochemical screening and measureable estimation of the percentage crude produces of chemical constituents of the plants studied showed that the herbal extract were rich in alkaloids, flavonoids, tannins and saponins ${ }^{(30)}$. They were known to show medicinal activity as well as exhibiting physiological activity, Steroids and phlobatannins were found to be present in all the plants. It has been found that some of these investigated plants contained steroidal compounds ${ }^{(31)}$.

Table 5: Preliminary Phytochemical screening of Piper cubeba.

\begin{tabular}{|c|c|c|c|c|c|c|}
\hline Plant's Name & Alkaloid & Glycosides & $\begin{array}{c}\text { Terpenoid } \\
\text { Steroid }\end{array}$ & Flavonoid & Tannins & $\begin{array}{c}\text { Anthra - } \\
\text { quinones }\end{array}$ \\
\hline $\begin{array}{c}P . \text { Cubeba } \\
\text { extract }\end{array}$ & ++ & ++ & -- & ++ & ++ & ++ \\
\hline
\end{tabular}

(++) Denotes average and (--) denotes absent.

\section{Antibacterial Analysis of $P$. Cubeba Extract}

The antibacterial activities the $100 \mathrm{mg} / \mathrm{ml}$ of P.cubeba extracts on S. aureus, Koucria rosia, E.coli and P.aerginosa the results shown in the (table 4) that the higher inhibition zone $S$. aureus $11.2 \mathrm{mg}$ that nears with antibiotic and the lowest inhibition $6.1 \mathrm{~mm}$ with Koucria rosia and $7.3 \mathrm{~mm}$ with E.coli. The antimicrobial potency of plants is believed to be due to tannins, saponins, phenolic compounds, essential oils and flavonoids. It is exciting to note that even herbal extracts of plants revealed good action against multidrug resilient strains where modern antibiotic therapy has failed. As per our results, suggesting that these extracts inhibited growth of the test microorganisms while being bactericidal/ fungicidal at higher concentrations $^{.(22)}$. In one study, the antibacterial effects of four types of $P$. cubeba extracts on some Gram-positive bacteria like Staphylococcus aureus and Gram-negative ones, like E. 
coli. The results demonstrated that the E. coli was more resistant to the plant extract than S. aureus. Because lipopolysaccharide (LPS) layer of gram- negative bacteria in outer membrane have a high hydrophobicity which acts as a strong permeability barrier against hydrophobic molecules. Hydrophobic molecules can pass through cell wall of grampositive bacteria easier than the gram-negative bacteria because cell wall of the gram-positive bacteria contained only peptidoglycan ${ }^{(23)}$. The mechanism of antibacterial action of spices and derivatives is not yet clear.) which involve: hydrophobic and hydrogen bonding of phenolic compounds to membrane proteins, followed by partition in the lipid bilayer; perturbation of membrane permeability consequent to its expansion and increased fluidity causing the inhibition of membrane embedded enzymes; membrane disruption; destruction of electrons transport systems and cell wall perturbation ${ }^{(24)}$.

Table 6: Antibacterial study of $P$. cubeba extract

\begin{tabular}{|c|c|c|c|}
\hline \multirow{2}{*}{ Microbial Strains } & Plant Extract & $\begin{array}{c}\text { Inhibition zone } \\
(\mathbf{m m})\end{array}$ & Control \\
\hline S.aureus & $100 \mathrm{mg} / \mathrm{ml}$ & 11.2 & $14.5 \mathrm{VA}$ \\
\hline Koucria rosia & $100 \mathrm{mg} / \mathrm{ml}$ & 6.1 & $11 \mathrm{RA}$ \\
\hline E.coli & $100 \mathrm{mg} / \mathrm{ml}$ & 7.3 & $18 \mathrm{AK}$ \\
\hline P.aerginosa & $100 \mathrm{mg} / \mathrm{ml}$ & 9 & $20 \mathrm{IPM}$ \\
\hline
\end{tabular}

(VA). Vancomycin. (RA) Rifampin. (AK) Amikacin. (IPM) Imipenam

\section{CONCLUSION}

The phytochemical tests indicated the presence of alkaloids, glycosides, tannins, and flavonoids in the crude aqueous extract. Several of such compounds are known to possess potent antioxidant activity and total carbohydrates. Some of these constituents have already been isolated from this plant. The results of antioxidant activity indicate higher free radical scavenging activity in aqueous extracts of $P$. Cubeba due to presence of phytochemical constituents especially polyphenols. The antibacterial effect of aqueous extract of $P$. Cubeba was the stronger in comparison, it recommended using the plant extract to preserve the food, and prevent the contamination. This experiment supports that these fruits can be used in pharmaceutical industries as natural antioxidants. 


\section{ACKNOWLEDGMENT}

The authors are thankful to University of Garmian, we are also thankful to Head of the Department of chemistry and biology, College education for carrying out the experimental work. Finally we are thankful to Dr. Ayad, Mr. Karzan and Mr. Ali Alazawi.

\section{References}

1. R. N. Chopra, S. L. Nayer, and I. C. Chopra, Glossary of Indian Medicinal Plants, Council of Scientific \& Industrial Research (India), NISCAIR, New Delhi, India, 1956.

2. M. M. Gayasuddin, S. S. Shakil, and S. Kavimani, "Effect of ethanolic extract of $P$. Cubeba Linn. fruits on activity of pioglitazone," International Journal of Pharmacy \& Industrial Research, vol. 1, pp. 312-314, 2011.

3. Jensen S, Hansen J and Boll PM (1993) Lignans and neolignans from Piperaceae (Review). Phytochemistry 33:523-530.

4. Balasundram, N., K. Sundram and S. Sammar. Phenolic compounds in plants and agriindustrial by-products. Antioxidant activity, occurrence and was active potential uses, Food Chem., 1: 191-203. 2006.

5. Abah, S.E. and G. Abah. Antimicrobial and Antioxidant Potentials of Agaricusbisporus. Advances in Biological Research. 4 (5): 277- 282. 2010.

6. Lawless and Julia. The illustrated encyclopedia of essential oils: the complete guide to the use of oils in aromatherapy and herbalism, Element Books. (1995).

7. Taga, M.S., E.E. Miller and D.E. Pratt,. Chia seeds as a source of natural lipid antioxidants. J. Am. Oil Chem. Soc., 61: 928-931, 1984.

8. Kekuda, P.T.R; Rakesh, K.N.; Syed J. and Dileep, N. Antibacterial and antioxidant activities of Streptomyces species SRDP-H03 isolated from soil of Hosudi, Karantaka, India. J. of Drug Deli. \& Thera., 3(4): 47-53 47, 2013.

9. Mukhtar, L. Antifungal activity of Cuscuta reflexa. Institute of Mycology and Plant Pathology, University of the Punjab, Lahore, Pakistan Jou of Bio Sci ., Vol.10 ( 11 ) ,pp: 124-129, 2009.

10. Trease G.E., Evans W.C. Pharmacognosy, 12th edn. Bailliere Tindall, East Bourne, 1983. BN213UN.

11. Venkata, R., Samuel, L., Pardha, S.M., Narashimha, R. Naga, V.K.A., Sudhakar, M., and Radhakrishnan, T.M. Antibacterial, antioxidant activity and GC-MS Analysis of Eupatorium odoratum. Asian J. Pharm. Clin. Res., 5. Suppl 2, 0974-2441, 2012. 
12. Margareth B. C. Gallo., Miranda J. Sarachine. Biological activates of Lupeol. International journal of biomedical and pharmaceutical sciences 3 (special issue 1): 46-66, 2009.

13. Hema, R., Kumaravel, S., and Alagusundaram. GC/MS Determination of Bioactive components of Murraya koenigii. Journal of American Science, 7(1), 2011.

14. Pinelo M, Manzocco L, Nunez MJ, Nicoli MC. Interaction among phenols in food fortification: negative synergism on antioxidant capacity. J Agric Food Chem52(5):117780, 2004

15. Halvorsen R, Carlsen M, Phillips K, Bohn S, Holte K, Jacobs D, Jr, Blonhoff R. Content of redox-active compounds (ie, antioxidants) in foods consumed in the United States. Am J Clin Nut 84:95-135, 2006.

16. Koleva I.I.,. Van Beek T.A, Linssen J.P.H., de Groot A. and. Evstatieva L.N. Screening of plant extracts for antioxidant activity: A comparative study on three testing methods. Phytochem. Anal. 2002;(13).

17. Geldof N, Engeseth NJ. Antioxidant capacity of honeys from various floral sources based on the determination of oxygen radical absorbance capacity and inhibition of in vitro lipoprotein oxidation in human serum samples. J Agric Food Chem50:3050-5, 2002.

18. Nooman Khalaf A., Shakya Ashok K., Al-OZthman Atif, Zaha, El-agbar Farah Husni. Antioxidant Activity of Some Common Plants. Turk J Biol. 2008; 32:51-55.

19. Choi E.M., Hwang J.K. Effect of some medicinal plants on plasma antioxidant system and lipid levels in rats. Phytother Res. 2005;(19):382-386.

20. Tognetti, R.; Johnson, J.D. The effect of elevated atmospheric CO2 concentration and nutrient supply on gas exchange, carbohydrates and foliar phenolics concentration in live oak (Quercus virginiana Mill.) seedlings. Ann. For. Sci. 1999, 56, 379-389.

21. Den-Hertog, J.; Stulen, L.; Fonseca, E.; Delea, P. Modulation of carbon and nitrogen allocation in Urtica diocia and Plantago major by elevated CO2: Impact of accumulation of non-structural carbohydrates and ontogenic drift. Physiol. Plant. 1996, 98, 77-88.

22. Aboaba, O.; Efuwape, B.M. Antibacterial Properties of Some Nigerian Species. Bio. Res. Comm. 2001, 13, 183-188.

23. Ababutain IM. Antimicrobial Activity of Ethanolic Extracts from Some Medicinal Plant. Australian J of Basic and Applied Sciences 2011; 5: 678-683.

24. Pundir RK, Jain P. Comparative Studies on the Antimicrobial Activity of Black Pepper (Piper Nigrum) and Turmeric (Curcuma Longa) Extracts. International J of Applied Biology and Pharmaceutical Technology 2010; I (2): 492-501. 
25. Adebisi, G.A., Oyeleke, G.A. "Studies on Ficus capensis (Fruit and Leaf): Proximate and Mineral Compositions". International Journal of Chemical Sciences, 7 (3), 1765-1761, 2009.

26. Papp, L.V., Lu, J., Holmgren, A., Khanna, K.K. "From Selenium to Selenoproteins: Synthesis, Identity, and Their Role in Human Health". Antioxidants \& redox signaling, 9 (7), 806-775, 2007.

27. Bongoni, R., Steenbekkers, L.P.A., Verkerk, R., van Boekel, M.A.J.S., Dekker, M. "Studying Consumer Behaviour Related to the Quality of Food A Case onVegetable reparation Affecting Sensory and Health Attributes". Trends i n Food Science \& Technology, 33 (2), 145-139, 2013.

28. Sies H., Stahl W. Vitamin E and C, beta carotene and other carotenoids as antioxidants. Am J Clin Nutr. 1995; 62:13115S-21S.

29. Vijayakumar R.S., Surya D., Nalini N. Antioxidant efficiency of black pepper and piperine in rats with high fat diet induced oxidative stress. Redox Rep. 2004;9(2):105110.

30. Atal C.K., Dubey A.K., Singh J. Biochemical basis of enhanceddrug availability by piperine, J. Exp. Ther. 1985; (232): 258-262.

31. Sofowara A. Medicinal plants and Traditional medicine in Africa. Spectrum Books Ltd, Ibadan, Nigeria. (1993) 289.

32. Harborne J.B. Phytochemical Methods, a guide to modern techniques of plant analysis, $3^{\text {rd }}$ Edn. Springer (India) Private Limited, NewDelhi (1998).

33. Mukherjee P.K.. Quality Control of Herbal Drugs, an approach to evaluation of botanicals, 1st Edn. Business Horizons, New Delhi, 2002.

34. Kim K.T., Yoo K.M., Lee J.W., Eom S.H., Hwang I.K., Lee C.Y. Protective effect of steamed American ginseng (Panax quinquefolius L.) on V79-4 cells induced by oxidative stress. J. Ethnopharm.2007;(111):443-445.

35. Aqil F., Ahmed I., Mehmood Z. Antioxidant and free radicalscavenging properties of twelve traditionally used Indian medicinal plants.Turk J Biol. 2006;(30): 177-183.

36. Dorman H.J., Deans S.G. Antimicrobial agents from plants:antibacterial activity of plant volatile oils. J Appl Microbiol.2000;(88):308-316.

37. Demiray S., Pintado M.E. and Castro P.M.L. Evaluation of phenolic profiles and antioxidant activities of Turkish medicinal plants Tilia argentea, Crataegi folium leaves and Polygonum bistorta roots.World Acad. Sci. Eng. Technol.,2009;(54):312-317. 